\begin{tabular}{|c|c|c|}
\hline 0,0286 & 636,8 & 102,8 \\
\hline 0,0278 & 613,5 & 98,8 \\
\hline 0,0280 & 618,1 & 99,6 \\
\hline 0,0271 & 631,3 & 101,6 \\
\hline 0,0278 & 615,0 & 99,1 \\
\hline 0,0288 & 630,6 & 101,5 \\
\hline \multicolumn{2}{|c|}{ X $=100,6 \% ; R S D=1,6 \%$} \\
\hline
\end{tabular}

Kết quả ở bảng 3 cho thấy: Với chương trình sắc ký đã chọn, phương pháp định lượng salbutamol sulfat có độ lặp lại cao, độ lệch chuẩn tương đối là 1,6\% (<2\%), đạt yêu cầu theo tiêu chuẩn quy định.

3.5. Kết quả thẩm định độ đúng của phương pháp. Tiến hành xác định độ đúng bằng phương pháp thêm chuẩn. Thêm một lượng salbutamol sulfat chuẩn khoảng 2,1mg vào mẫu thử sao cho nồng độ vẫn nằm trong khoảng tuyến tính đã khảo sát. Kết quả được trình bày ở bảng 4.

Bảng 4. Kết quả khảo sát độ đúng của phương pháp

\begin{tabular}{|c|c|c|c|}
$\begin{array}{c}\text { Lượng } \\
\text { chuẩn thêm } \\
\text { vào (mg) }\end{array}$ & $\begin{array}{c}\text { Diện tích pic } \\
\text { của mấu thử + } \\
\text { chuẩn(mAU.s) }\end{array}$ & $\begin{array}{c}\text { Lượng } \\
\text { chuấn tìm } \\
\text { thấy (mg) }\end{array}$ & $\begin{array}{c}\text { \% } \\
\text { tìm } \\
\text { thấy }\end{array}$ \\
\hline 2,1 & 955,2 & 2,15 & 102,4 \\
\hline 2,1 & 945,4 & 2,09 & 99,5 \\
\hline 2,1 & 943,7 & 2,08 & 99,1 \\
\hline 2,1 & 942,8 & 2,07 & 98,6 \\
\hline 2,1 & 950,8 & 2,12 & 100,1 \\
\hline 2,1 & 952,3 & 2,13 & 101,4 \\
\hline \multicolumn{2}{|c|}{$X=100,2 \%$ RSD $=1,4 \%$} \\
\hline
\end{tabular}

Kết quả ở bảng 4 cho thấy: Phương pháp có tỷ lệ thu hôi ở 6 mẫu khác nhau đạt từ 99,1 102,4\% đêu nằm trong khoảng 98 - 102\% so với lượng chuẩn thêm vào; RSD thu được bằng
$1,2 \%<2 \%$. Chứng tỏ phương pháp đã xây dựng có độ đúng cao.

*Tóm lại: Chương trình HPLC đã xây dựng có khoảng tuyến tính thích hợp, độ đúng, độ lặp lại cao và cho kết quả đáng tin cậy. Có thể áp dụng phương pháp HPLC với các điều kiện trên để xác định hàm lượng salbutamol sulfat trong phim salbutamol sulfat giải phóng nhanh.

\section{KẾT LUẬN}

- Đã lựa chọn điêuu kiện định lượng bằng sắc ký lỏng hiệu năng cao như sau: salbutamol sulfat chuẩn hoằc bột phim được hòa tan trong pha động để được nông độ khoảng $96 \mu \mathrm{g} / \mathrm{ml}$, tiến hành sắc ký và so sánh diện tích píc thu được. Điều kiện sắc ký: Cột sắc ký GRACE Apollo C18 $(4,6 \times 150 \mathrm{~mm}, 5 \mu \mathrm{m})$, nhiệt độ cột $25^{\circ} \mathrm{C}$, tốc độ dòng $1 \mathrm{ml} /$ phút, Detector UV tại bước sóng 276 nm, thể tích tiêm $20 \mu \mathrm{l}$, pha động gồm dung dịch natri dihydrophosphat $\mathrm{pH} 3,1$ và methanol (85:15).

- Phương pháp cũng được thẩm định đây đủ các chỉ tiêu theo hướng dẩn của $\mathrm{ICH}$ về thẩm định phương pháp phân tích.

\section{TÀI LIÊU THAM KHẢO}

1. Bộ Y tế (2002), Dược thư quốc gia Việt nam, NXB Y hoc, tr. 862-865.

2. Bộ Y tế (2009), Hóa dược 2, NXB Y học, tr. 451-452.

3. Dinge A., Nagarsenker M. (2008), Formulation and evaluation of fast dissolving films for delivery of triclosan to the oral cavity, AAPS Pharm. Sci. Tech., 9(2), pp. 349-356.

4. Verma R., Sanjay G. (2001), Current status of drug delivery technologies and future directions, Pharm. Technol., 25, pp. 1-14.

5. International Conference on Harmonisation (2005), ICH Q2 (R1) Validation of analytical procedures: Text and methodology.

\title{
TỐI ƯU CHO SỰ PHÁT TRIỂN CỦA PHÔI TRONG NỒNG Độ OXY 20\%: MÔI TRƯỜNG ĐƠN BƯỚC HAY ĐA BƯỚC?
}

\section{TÓM TẮT}

\author{
${ }^{1}$ Bệnh viện $16 A$ Hà Đông \\ ${ }^{2} \oplus H Q G$ Hà Nôi; \\ ${ }^{3}$ Học viện Quân y \\ Chiu trách nhiêm chính: Nguyễn Linh Chi \\ Email: linhchi148@gmail.com \\ Ngày nhận bài: 29/8/2021 \\ Ngày phản biên khoa học: 29/9/2021 \\ Ngày duyệt bài: 15/10/2021
}

\section{Nguyễn Linh Chi ${ }^{1,2}$, Ngô Thị Tường Châu ${ }^{2}$ Nguyễn Đình Tảo ${ }^{1}$, Nguyễn Ngọc Diệp ${ }^{3}$}

Do nhiều nguyên nhân, tình trang vô sinh nam nữ đang ngày môtt tăng cao. Điều này thúc đẩy các nhà khoa học tìm kiếm loại môi trường tối ưu, đây mạnh chất lượng nuôi cấy và nâng tỷ lệ thành công cho các cặp vợ chồng mong con. Trong công trình nghiên cứu này chúng tối đánh giá sư phát triển 1713 phôi từ giai đoạn hợp tử tới phôi nang trong thời gian 10/20192/2021. Nang trưởng thành được nuôi cấy trong môi trường đơn bước Global total ${ }^{\circledR}$ từ ngày 1 đến ngày 5 , hoăc nuôi cấy trong môi trường đa bước G1-PLUSTM đến ngày 3 , và thay sang môi trường G2-PLUSTM từ ngày 3 đến ngày $5 /$ ngày 6 . Kết quả cho thấy, môi 
trường đơn bước đã được đánh giá bước đầu là một sản phẩm nuôi cấy liên tục có hiệu quả: Tăng số lượng cũng như tỷ lệ phôi hình thái tốt và trung bình ở ngày 5 , tăng tỷ lệ phôi phát triển từ ngày 3 lên ngày 5 , mặc dù không có sự khác biệt giữa tỷ lệ thụ tinh và chất lượng phôi ngày 3 khi so sánh với môi trường đa bước.

Từ khóa: Môi trường nuôi cây, IVF, phôi tối ưu.

\section{SUMMARY}

SINGLE VERSUS SEQUENTIAL CULTURE MEDIUM: WHICH IS BETTER FOR EMBRYONIC DEVELOPMENT AT OXYGEN LEVEL OF $20 \%$ ?

Due to many reasons, along with the development of society, male and female infertility is increasing day by day. This reality promote scientists to research and find out the optimal types of cluture medium, improve the quality of culture as well as improve the success rate for couples expecting children. In this study, we evaluated the development of 1713 embryos (taken from 165 patient pairs) from the zygote to blastocyst stage between October 2019 and February 2021, cultured in concentrations of atmospheric oxygen level $20 \%$. Mature follicles were cultured in single step medium (Global total $\AA$ ) from day 1 to day 5 , or cultured in multistep medium G1-PLUSTM (Vitrolife) until day 3 , and changed to G2-PLUSTM medium (Vitrolife) from day 3 to day 5/day 6 . The results showed that the single step medium was initially evaluated as an effective continuous culture product: Increase the quantity as well as percentage of embryos with good- and average-morphology on day 5 , increased embryo development rate from day 3 to day 5 , although there was no difference between fertilization rate and day 3 embryo quality when compared with the sequential medium.

Keywords: Culture medium, IVF, optimal embryo.

\section{I. ĐẶT VẤN ĐỀ}

Cùng với sự phát triển của xã hội, kỹ thuật IVF đang ngày càng được hoàn thiện hơn để mang đến thành công nhất cho các cặp vợ chồng vô sinh hiếm muộn. Bên cạnh việc đảm bảo các yếu tố vật lý trong tử nuối cấy và phòng labo, các nhà khoa học vẫn đang không ngừng nghiên cứu và tìm kiếm ra loại môi trường nuôi cây tối ưu cho phôi

phát triển. Làm thế nào để đạt tối ưu số lượng và chất lượng phôi nang khi nuôi cấy bên ngoài môi trường cơ thể me? Hiện nay, có rất nhiều cuộc thảo luận về thành phần lý tưởng của môi trường nuôi cấy với hai quan điểm đối lập "trở về tự nhiên" và "lựa chọn tự do của phôi".

Theo nguyên tắc "trở lại tự nhiên", môi trường đa bước bắt chước điều kiện tự nhiên khi hợp tử di chuyển từ ống dẫn trứng đến tử cung trong quá trình phát triển. Để đáp ứng nhu cầu của phôi tại từng thời điểm phát triển và tối ưu hóa chất lượng phôi, môi trường tuần tự chứa thành phần khác nhau trong các ngày nuôi cấy khác nhau. Các chế phẩm "lý tưởng" này dựa trên các nghiên cứu trên mô hình động vật báo cáo sự thay đổi về nhu cầu năng lượng khi quá trình nuôi cấy trong ống nghiệm của phôi trước khi làm tổ phát triển theo thời gian [1]. Theo nguyên tắc "Lựa chọn tự do của phôi", phôi được nuôi cấy trong một môi trường duy nhất không đổi - môi trường nuôi cây đơn bước, chứa tất cả các thành phần cần thiết trong quá trình phát triển của phôi và thành phần của môi trường duy nhất này không thay đổi trong quá trình nuôi cây phôi. Mặc dù cả 2 loại môi trường đều thể hiện được những ưu điểm của nó, nhưng hiện nay chưa thực sự lựa chọn được loại môi trường nuôi cấy nào (đa bước hay đơ̛n bước) để giúp chất lượng phôi tốt nhất vào ngày thứ 5 .

Đã có nhiều bài báo nghiên cứu và so sánh hai loại môi trường này, nhưng các nghiên cứu không sử dụng hãng mối trường nuôii cây giống nhau [2] [3] [4]. Thực chất, mỗi hãng môi trường sẽ có những bí quyết và hàm lượng hợp chất riêng trong từng loai sản phẩm của họ, sự khác nhau này có thể dấn đến các kết quả nuổi cấy khác nhau về ảnh hưởng đến tỷ lệ phát triển phôi từ ngày 3 lên ngày 5 và ảnh hưởng đến hình thái phôi ngày 5 . Để đạt được mục tiêu cuối cùng trong IVF là bệnh nhần có thai lâm sàng, thì điều quan trọng nhất trong phòng labo là làm sao để nuôi cấy được phôi phát triển lên phôi ngày 5 tối ưu nhất.

Mục tiêu nghiên cứu này là so sánh chất lượng phôi ngày 5 khi nuôi cấy trong môi trường đớn bước (Global total) hoặc trong môi trường đa bước (G1-Plus ${ }^{T M} / G 2-P l u s^{T M}$ ). Ngoài ra, cũng so sánh cả chất lượng phôi ngày 3 và tỷ lệ phát triển lên phôi ngày 5 , tổng số lượng phôi ngày 5 ở cả 2 nhóm.

\section{II. ĐỐI TƯợNG VÀ PHƯƠNG PHÁP NGHIÊN CỨU}

Nghiên cứu được thực hiên từ tháng 10/2019 đến tháng 2/2021 với các chu kỳ IVF tại Trung tâm hỗ trợ sinh sản Bệnh viện Đa khoa 16A Hà Đông. Nghiên cứu sử dụng môi trường nuôi cấy đa bước $\mathrm{G}-1, \mathrm{G}-2$ plus của hãng Vitrolife-Thụy Điển và môi trường nuôi cãy đơn bước Life Global - Mỹ, các chu kỳ IVF được sử dụng ngẫu nhiên hai loại môi trường này trong suốt giai đoạn nghiên cứu. Các chu kỳ IVF / ICSI (tiêm tinh trùng vào bào tương noãn) được thực hiện trong cùng một phòng khám và phòng Labo với cùng quy trình lâm sàng, quy trình phòng thí nghiệm và vật liệu tiếp xúc, nồng độ oxy sử dụng trong tủ nuôi cấy là $20 \%$. Không có sự thay đổi nhân viên phòng thí nghiệm phôi học, thay đổi duy nhất là thay đổi về môi trường nuối cấy. Đã có sự chấp thuận của Hội đồng đạo đức 
Bệnh viện 16A Hà Đông, dữ liệu được thu thập từ hồ sở bệnh án của Trung tâm Nghiên cứu lựa chọn những bệnh nhân có ít nhất 4 nang thứ cấp vào ngày 2 chu kì kinh, tuổi me $<37$ tuổi và chỉ số nội tiết $A M H>1,2 \mathrm{ng} / \mathrm{mL}$. Tổng số chu kỳ IVF được đưa vào nghiên cứu là 165 chu kỳ với 1423 phổi ngày 3 và 973 phôi ngày 5 .

Bệnh nhân sau khi được kích thích buồng trứng có kiểm soát từ 9 đến 12 ngày, được hút nang qua hướng dẫn siêu âm (36 giờ sau hCG). Nang trứng được lấy ra và chuyển đến phòng thí nghiệm trong 2 phút, được đặt trong lồng ấp 2-4 giờ để chuẩn bị tiêm tinh trùng vào tế bào chất (ICSI).

Sau ICSI, tất cả tế bào trứng được đặt vào môi trường rửa trứng và được phân chia ngẫu nhiên thành hai nhóm nuôi cấy trong 2 môi trường khác nhau (Life Global hoặc Vitrolife). Tất cả sự phát triển phôi trong ống nghiệm được thực hiện trong tủ nuôi cấy phôi K- System G210 và tủ Thermo 371. Mỗi loại tủ được kiểm soát $\mathrm{pH}$ bằng cách điều chỉnh nồng độ $\mathrm{CO}_{2}$ (chuẩn độ ở mức 5,0-6,5\%). Tất cả các phôi đều trải qua phân loại chất lượng tiêu chuẩn của ngày 3 để đánh giá số lượng tế bào, tính đối xứng, sự phân mảnh và chỉ định ở mức độ loại 1 , loại 2, loại 3. Đến ngày 5 phát triển, phôi được đánh giá thêm một lân nữa dựa vào các tiêu chí: Độ giãn nở của khoảng phôi, thể tích ICM, thể tích lá nuôi (theo các mức độ: tốt, khá tốt, khá và trung bình). Phân loại phôi ngày 3 và ngày 5 theo theo phương pháp phân loại phôi của đồng thuân Istanbul 2011 [5]. So sánh các nhóm phát triển phôi bằng phương pháp thống kê mô tả định lượng và định tính kết hợp sử dụng kiểm định t-test.

\section{KẾT QUẢ NGHIÊN CứU}

Trong khoảng thời gian 1,5 năm (tháng 10 năm 2019 _tháng 2 năm 2021), tổng số có 165 chu kỳ thụ tinh ống nghiệm được thực hiện với ít nhất một trứng được thụ tinh. Trong đó, 92 chu kỳ sử dụng môi trường nuôi cấy đơn bước trong khi 73 chu kỳ sử dụng môi trường nuôi cây đa bước. Trong các chu kỳ IVF, số lượng phôi ngày 1 của nhóm đa bước cao hơn so với nhóm đơn bước $(11,11 \pm 1,50$ so với $9,80 \pm 0,99)$ nhưng không có ý nghĩa thống kê $(p>0,05)$, về tỷ lệ thụ tinh không có sự khác biệt giữa hai môi trường nuôi cấy, bất kể tuổi tác (Bảng 1).

Bảng 1. Phân loai thông tin cơ bản của bênh nhân

\begin{tabular}{|c|c|c|c|}
\hline Đặc điếm & MT đơn bước & MT đa bước & Giá trị t \\
\hline Số lượng bệnh nhân & 92 & 73 & \\
\hline Tuô̂i & $31,27 \pm 0,88$ & $31,45 \pm 1,01$ & $0,360(p=[0,25-0,5])$ \\
\hline AMH (mg/mL) & $3,63 \pm 0,44$ & $3,99 \pm 0,73$ & $0,8346(p=[0,2-0,25])$ \\
\hline Số noân/chu kỳ & $12,64 \pm 1,16$ & $13,45 \pm 1,63$ & $0,8072(p=[0,2-0,25])$ \\
\hline SL phôi ngày $1 /$ chu kỳ & $9,80 \pm 0,99$ & $11,11 \pm 1,50$ & $1,4480(p=[0,05-0,1])$ \\
\hline Tỷ lẹ thụ tinh & $77,40 \pm 3,04$ & $78,82 \pm 3,33$ & $0,0340(p=[0,25-0,5])$ \\
\hline
\end{tabular}

Đánh giá chất lượng phôi ngày 3 cho thấy, phôi ở hai nhóm được nuôi cấy trong môi trường khác nhau có tỷ lê chiếm chủ yếu là phôi loại tốt và trung bình, trong đó, số lượng phôi trung bình chiếm tỷ lệ cao nhất ở cả hai nhóm. Các chỉ số về số lượng và tỷ lệ phôi loại tốt và trung bình cũng như tỷ lệ phôi phát triển ngày 3 thành công của 2 nhóm nghiêm cứu không có sự khác biệt rõ rệt $(p>0,25)$. ở nhóm môi trường đơn bước, số lượng phôi mỗi chu kỳ và số lượng phôi tốt thẩp hơn so với môi trường đa bước, tuy nhiên không có ý nghĩa thống kê ( $p>0,05)$ (Bảng 2).

Bảng 2. Chất lượng phôi ngày 3 và ngày 5 của các bệnh nhân hai nhóm.

\begin{tabular}{|c|c|c|c|c|}
\hline \multirow{2}{*}{ Chất lượng phôi } & \multicolumn{2}{|c|}{ Môi trường đơn bước } & \multicolumn{2}{|c|}{ Môi trường đa bước } \\
\hline & Phôi ngày 3 & Phôi ngày 5 & Phôi ngày 3 & Phôi ngày 5 \\
\hline Tống số lượng phôi & 747 & 543 & 676 & 430 \\
\hline SL phôi môi chu kỳ & $8,12 \pm 0,85$ & $5,90 \pm 0,60$ & $9,26 \pm 1,32$ & $5,89 \pm 0,94$ \\
\hline Số lượng phôi tốt & 206 & 296 & 179 & 219 \\
\hline SL phôi tốt môi chu kỳ & $2,24 \pm 0,44$ & $3,22 \pm 0,53$ & $2,45 \pm 0,64$ & $3,00 \pm 0,65$ \\
\hline Tỷ lệ phôi tốt & $26,71 \pm 4,24$ & $50,66 \pm 6,19$ & $23,37 \pm 4,47$ & $48,76 \pm 7,11$ \\
\hline SL phối loại trung bình & 401 & 140 & 353 & 101 \\
\hline SL phôi loại TB môi chu kỳ & $4,36 \pm 0,57$ & $1,52 \pm 0,27$ & $4,84 \pm 0,77$ & $1,38 \pm 0,38$ \\
\hline Tỷ lệ phôi loại TB & $53,13 \pm 4,41$ & $26,66 \pm 5,14$ & $54,62 \pm 5,34$ & $22,21 \pm 5,98$ \\
\hline Tỷ lệ loại tốt và TB & $79,84 \pm 4,79$ & $77,32 \pm 5,27$ & $77,99 \pm 5,03$ & $70,97 \pm 5,67$ \\
\hline Số lượng phôi xấu & 140 & 107 & 144 & 110 \\
\hline SL phối xấu môi CK & $1,52 \pm 0,38$ & $1,16 \pm 0,26$ & $1,97 \pm 0,49$ & $1,51 \pm 0,25$ \\
\hline Tỷ lệ thành công & $84,09 \pm 3,21$ & $62,16 \pm 3,24$ & $84,09 \pm 2,15$ & $53,05 \pm 4,50$ \\
\hline
\end{tabular}


Số lượng phôi ngày 5 mỗi chu kỳ cũng như số lượng phôi loại tốt, phôi loại trung bình của mỗi chu kỳ IVF/ICSI khi được nuôi cấy bằng môi trường đơn bước Life Global không có sự khác biệt nào so khi được nuôi cấy với Vitrolife $(p>0,25)$, trong khi số lượng phôi xấu của nhóm đa bước cao hơn so với nhóm đơn bước có ý nghĩa thống kê $(1,51 \pm 0,25$ so với $1,16 \pm 0,26$ với $\mathrm{p}<0,05)$. Về tỷ lệ các loại phôi, tỷ lệ phôi tốt và tỷ lệ phôi trung bình ngày 5 ở 2 nhóm đơn bước và đa bước không có sự khác biệt $(p>0,05)$, nhưng tỷ lệ nhóm phôi "tốt và trung bình", tỷ lệ phôi phát triển ngày 5 của nhóm đơn bước cao hơn so với nhóm đa bước $(p<0,05)$.

Khi so sánh theo lứa tuổi của bệnh nhân của 2 nhóm nghiêm cứu nhận thấy, không có sự khác biệt nhiều về số lượng và chất lượng phôi ngày 1 , ngày 3 , ngày 5 và̀ tỷ lệ thành công của 2 nhóm theo lứa tuổi (Bảng 3).

Bảng 3: Sự phát triển phôi phân loại theo độ tuổi khi nuôi cây trong hại loại môi trường

\begin{tabular}{|c|c|c|c|c|c|c|}
\hline \multirow{2}{*}{ Đặc điểm } & \multicolumn{2}{|c|}{ Dưới 26 tuối } & \multicolumn{2}{|c|}{ Từ 26-30 tuối } & \multicolumn{2}{|c|}{ Trên 30 tuối } \\
\hline & on bước & Đa bước & on bước & Đa bước & Đơn bước & Đa bước \\
\hline Số I & & & 27 & 23 & 54 & 43 \\
\hline & $36>2+3$ & 57 & 7 & 91 & 2 & \\
\hline & & & & & & \\
\hline SL & & 8 & + \pm 1 & $1 . / 0 \pm$ & 04 & 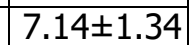 \\
\hline $\begin{array}{r}\text { Số lượ } \\
\text { n }\end{array}$ & $2.64 \pm 1.18$ & $7+233$ & 77 & $2.87 \pm 1.51$ & $11 \pm 0.61$ & $88+0$ \\
\hline $\begin{array}{r}\mathrm{L} \text { phô } \\
\mathrm{n}\end{array}$ & \pm 1.95 & $86 \pm 2.76$ & 33 & 47 & 0.63 & $3.74 \pm 0.7$ \\
\hline $\begin{array}{l}\text { Tỷ lệ } \\
\text { trung }\end{array}$ & 7 & 4 & 4 & & 23 & $78.98 \pm 6$ \\
\hline Tỷ lệ & $.15 \pm 8.53$ & $7 \pm 6.34$ & $72 \pm 6.34$ & $2.75 \pm 3.34$ & $.56 \pm 4.17$ & \pm 3 \\
\hline SL p & $64 \pm 2.20$ & $86 \pm 2.43$ & $59 \pm$ & \pm 1 & $20 \pm 0.76$ & $4.44 \pm 0.9$ \\
\hline Số lự & 4. & $5.00 \pm 2.04$ & $400+080$ & $3.91 \pm 1.43$ & $263+070$ & $219+06$ \\
\hline $\begin{array}{r}\text { SL phôi } \\
\text { ng }\end{array}$ & 1. & $1.86 \pm 1.26$ & $.37 \pm 0.40$ & & & 1.071 .0$. \\
\hline & $78 \times-8$ & $75.54 \pm 10.41$ & 6 & $75.37 \pm 7.52$ & 0 & $67.87 \pm 8$ \\
\hline ông & $.95=$ & $54.18 \pm 9.55$ & $.62 \pm 6.45$ & $33.8 / \pm 8$ & 2.4 & $52.42 \pm 5.9$ \\
\hline ỷ lệ ngày $5 /$ ngày 3 & $7.45 \pm 6.48$ & $.86 \pm 13.72$ & $7.19 \pm 5.03$ & $4.65 \pm 10.0$ & $4.28 \pm 3.88$ & $2.40 \pm 7$ \\
\hline
\end{tabular}

Nghiên cứu so sánh ngẫu nhiên 1713 phôi của 165 chu kỳ IVF nghiên cứu, chia đều thành 2 nhóm được nuôi cây trong 2 loại môi trường: Môi trường Total-Global (môi trường nuôi cấy liên tục) và môi trường Vitrolife (môi trường nuôi cấy phôi từng giai đoạn), với nồng độ oxy $20 \%$. Không có sự khác biệt nhiều về chất lượng phôi ngày 3 , nhưng nhìn chung môi trường đơn bước Global đã nuôi cây được phôi nang lên ngày 5 phát triển tốt hơn, thể hiện ở tỷ lệ phôi nang phát triển từ ngày 3 và ngày 1 , hình thái loại tốt và trung bình (ở cả nhóm phôi N3 và N5) cao hơn hẳn so với môi trường đa bước. Sự khác biệt về chất lượng phôi nang đã chứng minh được việc nuôi cấy phôi bên ngoài bằng cùng 1 môi trường hoàn toàn có thể phát triển phôi tốt hơn so với phải tách nhiều môi trường khi nuôi cây phôi. Nhìn chung, khả năng phát triển phôi ngày
3 của hai loại môi trường tương đối tương tự như các tỷ lể đã được công bố trước đây. Tuy nhiên, phần lớn các nghiên cứu trước đây không so sánh tỷ lệ thụ tinh hoặc cho kết quả thụ tinh của nhóm nuôi cấy đơn bước tốt hơn đa bước. Bên cạnh đó, các nghiên cứu trước đây sử dụng các cặp nhóm môi trường môi trường đơn bước/đa bước của các hãng thương mại khác nhau.

\section{BÀN LUẬN}

Trong nghiên cứu này, số lượng bênh nhân, tuổi, chỉ số nội tiết AMH là tương tự nhau ở cả 2 nhóm; vì vậy, có thể so sánh khách quan giữa 2 nhóm môi trường. Chúng tôi không tìm thấy sự khác biệt trong tỷ lệ thụ tinh, tỷ lệ phát triển phôi ngày 3 , chất lượng phôi ngày 3 (Bảng 2), điều này cùng quan điểm với một số nghiên cứu trước đây [2] [3] [4]. 
Mặc dù công thức chính xác của các thành phần nuôi cấy phôi trong hai loại môi trường không được tiết lộ bởi các nhà sản xuất, có một số nghiên cứu độc lập đã xác định được các thành phần chính trong môi trường nuôi cấy phôi người [6] [7]. Theo đó, có một số axit amin là thiết yếu trong thành phần nuôi cấy (là thành phần thiết yếu trong tử cung vòi trứng người mẹ), tuy nhiên theo thời gian chúng sẽ tự phân hủy và giải phóng amoniac vào môi trường nuôi cãy, và ảnh hưởng tiêu cực đến phôi [7]. Trong nghiên cứu của Iratxe và cộng sự, có sự khác biệt nhỏ trong một số sxiamin: môi trường đơn chứa một số axit amin nhất định như Cystine, Histidine, Isoleucine, Leucine hoặc Lysine, không có trong môi trường đa bước; và các chất nền năng lượng khác như glucose, lactate hoặc piruvate không có trong môi trường đa bước [3]. Sự khác biệt về thành phần môi trường nuôi cây là một trong những yếu tố dẫn đến sự khác nhau trong hình thành và phát triển phôi [8]. Mặc dù không có nhiều bằng chứng rõ rệt về sự khác biệt, nhưng tổng quan cho thây sử dụng môi trường đơn bước mang lại kết quả nuôi phôi tốt hơn.

Trên thực tế, khi nuôi cấy phôi người bằng môi trường đơn bước còn có 1 lợi thế đáng chú ý: Giảm thao tác trên phôi người (không phải thay mới môi trường khi phôi ngày 3 ), điều này làm giảm stress cho phôi, giúp giảm các nhầm lẫn sai sót trong thao tác, giảm chi phí nhân công và giảm chi phí vật tư tiêu hao, môi trường. Mặc dù có nhiều nghiên cứu về lĩnh vực này, nhưng không có hai nghiên cứu nào cùng so sánh một loại môi trường nuôi cấy, cùng một quy trình thao tác, và cùng đưa ra một kết quả giống hệt nhau [2] [3] [4]. Do vậy, việc nghiên cứu thêm về so sánh sự khác biệt giữa kết quả nuôi cấy phôi khi nuôi cấy bằng môi trường đơn bước và đa bước là cần thiết để đạt được kết luận chắc chắn hơn liên quan hiệu quả nuôi cấy phôi. Trong nghiên cứu của chúng tôi, mặc dù chỉ có ý nghĩa thống kê khác biệt với phôi ngày 5 , tuy nhiên các thông số khác cũng cho thây việc nuôi cấy phôi bằng môi trường đớn bước có kết quả tốt hơn so với môi trường đa bước. Mặc dù vậy, vẫn cần có nhiều các nghiên thử nghiệm hơn để cho ra kết luận cuối cùng về môi trường nuôi cấy phôi tối ưu.

\section{KẾT LUẬN}

Tỷ lệ thụ tinh và chất lượng phôi ngày 3 không có sự khác biệt khi nuôi cấy trong hai loại môi trường khác nhau. Tuy nhiên, khi nuôi cấy phôi trong môi trường đơn bước ngày 5 cho kết quả tốt hơn so với nuôi cấy trong môi trường đa bước. Cụ thể, số lượng phôi xấu của nhóm đa bước cao hơn so với nhóm đơn bước có ý nghĩa thống kê $(1.51 \pm 0.25$ so với $1.16 \pm 0.26$ với $\mathrm{p}<0.05)$; Tỷ lệ nhóm phôi "tốt và trung bình", tỷ lệ phôi phát triển ngày 5 so với ngày 3 và tỷ lệ phát triển phôi nang từ lúc thụ tinh của nhóm đơn bước cao hơn so với nhóm đa bước $(p<0.05)$.

Tổng quan cho thãy, môi trường nuôi cãy đơn bước mang lại hiệu quả nuôi cấy phôi nang tốt hơn so với môi trường đa bước. Bên cạnh đó, việc sử dụng môi trường đơn bước cũng làm giảm các thao tác trên phôi người, tránh nhầm lẫn cho các chuyên viên phôi học trong thao tác phôi, giảm stress cho phôi.

\section{TÀI LIÊU THAM KHẢO}

1. Biggers JD, Summers MC, "Choosing a culture medium: making informed choices," Fertil Steril, pp. 90:473-483, 2008.

2. Ioannis A. Sfontouris \& Wellington P. Martins \& Carolina 0 Nastri, Iara G. R. Viana \& Paula A. Navarro \& Nick Raine-Fenning \& Sheryl van der Poel," "Blastocyst culture using single versus sequential media in clinical IVF: a systematic review and meta-analysis of randomize controlled trials," Assist Reprod Genet, vol. 33, pp. 1261-1272, 2016.

3. Iratxe López-Pelayo, Javier María GutiérrezRomero, Ana Isabel Mangano Armada, María Mercedes CaleroRuiz, Pablo Javier Moreno de Acevedo-Yagüe, "Comparison of two commercial embryo culture media (SAGE-1 step single medium vs. G1-PLUSTM/G2-PLUSTM sequential media): Influence on in vitro fertilization outcomes and human embryo quality," JBRA Assisted Reproduction 2018;22(2):128-133, 2018.

4. Pomeroy KO, Foley S, Faber B, Moffitt DV Johnson MD., "A comparison of sequential medium with non-sequential medium: do some patients' embryos culture better in one than in the other?" Reprod Fertil Develop; 21:162-3, 2018.

5. ALPHA Scientists in Reproductive Medicin, "The Istanbul consensus workshop on embryo assessment: proceedings of an expert meeting," Human Reproduction, Vol.26, No.6. 1270-1283, 2011.

6. Sfontouris IA, Kolibianakis EM, Lainas GT, Petsas GK, Tarlatzis BC, Lainas TG. Blastocyst Development in a Single Medium Compared to Sequential Media: A Prospective Study With Sibling Oocytes.," Reprod Sci. 24:1312-8. PMID: 28093041 DOI: 10.1177/ 1933719116687653, 2017;,

7. Morbeck DE, Baumann NA, Oglesbee D., "Composition of single-step media used for human embryo culture" Fertil Steril;107:1055-60. PMID: 28238490 DOI: 10.1016/j.fertnstert2017.01.007, 2017.


to blastocyst.," Fertil Steril.91:878-83. PMID: 18321494 DOI: 10.1016/j.fertnstert.2007.12.011, 2009. 